\title{
EVOLUÇÃO HISTÓRICA DA AÇÃO RESCISÓRIA
}

As origens da ação rescisória remontam à volta ao passado, iniciando-se com institutos correlatos talhados na Roma Antiga. ${ }^{1}$

Os romanos não concebiam, no tempo da vigência das legis actiones, a cassação da sentença nula. ${ }^{2} \mathrm{O}$ tema da sentença nula estava fora do sistema recursal. Também estava fora da possibilidade de ataque por ação autônoma. Em suma, o autor não contava com nenhum instrumento para impugnar a nulidade da sentença; todavia, o réu poderia se valer do vindex. Ele poderia atacar a sentença pelo

1 As origens históricas do próprio direito processual são arraigadas no direito material, pois não se concebia uma distinção, mesmo na Roma Antiga e no desenvolvimento durante a Idade Média. É moderna a noção da cientificidade do direito processual civil, aparecendo como disciplina autônoma em relação ao direito material apenas a partir do século XIX. Note-se que, a par de o processo civil ter ficado escondido em meio ao direito material, pois não se conhecia a sua autonomia, não se nega que houve influências marcantes dos procedimentos da aplicação do direito através dos tempos, em especial entre os romanos e alemães, bem como no direito canônico, todos marcantes em vários aspectos, como o principiológico, probatório e recursal. Vide, com proveito: WOLKMER, Antônio Carlos. Fundamentos de história do direito. 2. ed. Belo Horizonte: Del Rey, 2002. p. 87.

2 PACHECO, José da Silva. Evolução do processo civil brasileiro: desde as origens até o advento do novo milênio. 2. ed. Rio de Janeiro: Renovar, 1999. p. 22. 
fundamento da inexistência da decisão, mas corria o risco de sucumbir e, neste caso, ser condenado ao chamado duplum, ou seja, ser condenado em dobro do devido na sentença. Nesse caso, o vindex era um terceiro apresentado pelo réu para garantir o pagamento dessa dobra legal, era uma espécie de fiador. ${ }^{3}$

Paralelamente, reconhecia-se um ataque geral ao ato jurídico produzido pela sentença, admitindo o revocare e rescindere dentro do gênero restituere, uma espécie de pedido simples, que passou a ser utilizado no direito romano tanto no processo penal como no civil, respectivamente restitutio ex capite justitiae (restituição por justiça do imperador) e restitutio ex capite gratiae (restituição por graça do imperador). ${ }^{4}$

No período formulário foi estabelecida a igualdade entre as partes, redundando na retirada da necessidade de apresentação do vindex pelo réu e abrindo a possibilidade de o autor também se voltar contra a sentença nula. Foi instituída, dessa forma, a "ação rescisória", todavia com natureza declaratória, pois era vista sob a ótica da inexistência do julgado em face da nulidade e, bem assim, poderia ser arguida a inexistência diretamente na execução. Em verdade, os romanos não distinguiam causas de nulidade daquelas que remetiam à anulabilidade, entretanto tecnicamente somente era possível alegar error in procedendo para requerer a declaração de nulidade da sentença, pois o error in judicando não poderia ser impugnado, tanto no período das legis actiones como no das fórmulas. ${ }^{5}$

Posteriormente, com o surgimento do Império, foi introduzido o sistema da apelatio, que permitia o rejulgamento da causa com fundamento na impugnação da sentença por error in judicando. Em um primeiro momento, era competente o próprio Imperador para conhecer e julgar a apelação das causas julgadas pelos pretores; depois, esse poder de reexame foi delegado aos altos funcionários do Império Romano. ${ }^{6}$

O Direito alemão também experimentou inicialmente um período no qual prevaleceu a irrecorribilidade da sentença. Porém, em nome da justiça, logo houve o reposicionamento legislativo, criando-se dispositivo que permitiu recorrer-se tanto em face do erro de procedimento como do erro judiciário material. ${ }^{7}$

3 CALAMANDREI, Piero. La cassazione civile. Torino: Fratelli Bocca Editori, 1920. v. I, p. 32.

4 PONTES DE MIRANDA, Francisco Cavalcanti. Tratado da ação rescisória. 4. ed. Rio de Janeiro: Forense, 1964. p. 82.

5 CALAMANDREI, Piero. La teoria dell'error in iudicando nel diritto italiano intermedio. In: Studi sul processo civile. Padova: Cedam, 1930. v. I, p. 68.

6 CHIOVENDA, Giuseppe. Instituições de direito processual civil. Campinas: Bookseller, 1998. v. I, p. 182.

7 WOLKMER, Antônio Carlos. Fundamentos de história do direito, p. 87. 
Na Europa Medieval foi replicada a regra romana com o aperfeiçoamento introduzido pelo sistema processual alemão: tanto o error in procedendo (inexistência do julgado) como o error in judicando deveriam ser impugnados via recurso. Depois, veio a máxima de que às sentenças injustas se reservava o recurso, às sentenças nulas desafiava a querela nullitatis. Aliás, a ação rescisória é uma forma derivada da primitiva querela nullitatis; em sua origem é mais uma atividade do officium judicis do que o exercício de uma ação ou de um recurso. ${ }^{8}$

$\mathrm{Na}$ França, passou-se a admitir a nulidade da sentença via recursal, com os denominados requête civile e demande en cassation. Na Itália, da mesma forma, desenvolve-se a ideia da querela nullitatis insanabilis ou ação anulatória da sentença, introduzindo a revocazione e o ricorso per cassazione. Em parte semelhante à apelação, por ela se podia pedir ao juiz superior, dentro do prazo fixado em lei, um reexame mais rápido, uma vez preenchidos os requisitos de anulabilidade do julgado. Vencido o prazo, decaía qualquer possibilidade de impugnação do julgado. ${ }^{9}$

A orientação alemã foi divergente, o que, mais tarde, viria a influenciar o sistema processual brasileiro. Adotaram-se duas vias impugnativas apartadas dos recursos: nichtigkeitsklage (na qual se permitia pleitear a nulidade da sentença) e restitutionsklage (com o fim na restituição ao status quo ante).

$\mathrm{O}$ direito espanhol perfilhou um caminho intermediário: introduziu a revisão, uma verdadeira ação, e o recurso de cassación. ${ }^{10}$

Aderindo à corrente recursal, dispositivos similares vigeram nessa época em Portugal: a revisão e a revista.

Por volta de 1217, o sistema legislativo português previu que a coisa julgada poderia ser prejulgada quando fosse reconhecido erro, desde que houvesse prévia autorização do Rei, na época, D. Afonso II. Tal exigência de autorização real viria a cair no ano de 1340 para impugnação com fundamento na inexistência da sentença - na dicção da legislação medieval, motivada em "sentença nenhuma”,

8 LIEBMAN, Enrico Tullio. Anotações às instituições de direito processual, de Giuseppe Chiovenda. São Paulo: Saraiva, 1969. v. 3, p. 200; LIEBMAN, Enrico Tullio. Eficácia e autoridade da sentença. 3. ed. Rio de Janeiro: Forense, 1984.

9 CALAMANDREI, Piero. La cassazione civile, 1920, v. I, p. 138; CALAMANDREI, Piero. Direito processual civil. Tradução de Luiz Abezia e Sandra Drina Fernandez Barbery. Campinas: Bookseller, 1999. v. 3, p. 249-268; CHIOVENDA, Giuseppe. Instituições de direito processual civil. Tradução de Paolo Capitanio. Campinas: Bookseller, 1998. v. III, p. 249-284; TARZIA, Giuseppe. Profili della sentenza civile impugnabile. L'individuazione della sentenza. Publicazione della Facoltà di Giurisprudenza, Milano, 1967. p. 66-71.

10 FRANÇA, Limongi Rubens (Coord.). Enciclopédia Saraiva do Direito. São Paulo: Saraiva, 1977. v. 3, p. 492. 
ou seja, com base na sentença inexistente, o que se confundia com sentença nula. Essa sistemática se manteve nas Ordenações Afonsinas de 1446, nas Ordenações Manuelinas de 1512 e nas Ordenações Filipinas de 1603, ficando autorizada a revogação das sentenças nulas a qualquer tempo. Somente em 1832 viria uma alteração significativa: firmavam-se as hipóteses de ação de nulidade da sentença que seria restrita aos casos de comprovada concussão, peita, peculato ou suborno do julgador; todas as outras hipóteses de impugnação com base em ofensa ao Direito e todos os erros de procedimento desafiariam o chamado recurso de revista (espécie de apelação). ${ }^{11}$ O Regulamento 737 de 1850 não distinguiu, ao contrário, contribuiu para manter a confusão entre anulabilidade com nulidade e rescindibilidade, conforme o art. 681 daquele estatuto. Em 1926 viria a ser aprovada uma reforma processual no sistema português, mas sem novidades nesse particular. ${ }^{12}$ Em 1939, foi introduzido com o então novo Código de Processo Civil de Portugal o recurso de revisão, que, por sua vez, substituiu a ação de nulidade da sentença, mas o sistema manteve o recurso de revista. ${ }^{13}$

\subsection{NOTAS DE ALGUMAS LEGISLAÇÕES ESTRANGEIRAS NA MODERNIDADE}

Os sistemas legislativos atuais contemplam recursos (normalmente cassação, eventualmente compreendendo o rejulgamento) e ações como meio de impugnação de sentenças. $\mathrm{O}$ sistema processual brasileiro separa a ação rescisória para o ataque à sentença de mérito transitada em julgado.

A ciência jurídica evoluiu e se tornou pacífico esse entendimento: não se trata de sentença nula, anulável, nem inexistente, o que se ataca é uma sentença que existe, é válida e eficaz; daí o interesse em ajuizar uma ação para rescisão da sentença. O objeto da ação rescisória são vícios da sentença que, não sendo proposta a ação no prazo legal, acabam por se convalidar; ou até, dada a irrelevância jurídica da alegação posterior, seria como se nunca tivessem existido tais vícios, mantendo-se válida a sentença para todos os efeitos jurídicos. Nesse sentido, atos jurídicos nulos são mais que simples sujeição ao regime rescisório.

Algumas legislações concebem a rescindibilidade dentro do sistema recursal, não necessitando de ajuizamento de ação, adotando apenas prazo mais dilatado,

11 "O Brasil, tendo sido colônia e depois fazendo parte do Reino de Portugal, recebeu o seu Direito, que aqui vigorou, mesmo após nossa independência política.” (VILLAR, Willard de Castro. Medidas cautelares. São Paulo: RT, 1971. p. 66).

12 PONTES DE MIRANDA, Francisco Cavalcanti. Tratado da ação rescisória. Campinas: Bookseller, 1998. p. 119.

13 VALLE, Cristino Almeida do. Teoria e prática da ação rescisória. 3. ed. Rio de Janeiro: Aide, 1990. p. 9. 
em geral um ano. Para citar alguns: Chile, recurso de revisión (art. 811); França, recours en revision (art. 593); Uruguai, recurso de nulidad (art. 670); Portugal, revisão, com prazo de 30 dias (arts. 771 e 772 ) - todos dispositivos dos respectivos Códigos de Processo Civil. Outros possuem rescindibilidade distinta dos recursos, como na Itália, revocazione (arts. 395 e 396), ${ }^{14}$ e na Alemanha, Wiederaufnabme des Verfahrens, $\mathbb{S} 5579$ e 580 ZPO. Na Espanha (revisión de sentencias firmes, arts. 509 a 516 da Ley de Enjuiciamiento Civil), bem como no México, ${ }^{15}$ admite-se a cassação da sentença transitada em julgado, da sentença exarada com vício de incompetência absoluta ou em face de contrariedade a literal disposição de lei. ${ }^{16}$

$\mathrm{Na}$ Alemanha a impugnação da sentença transitada em julgado, a chamada retomada do processo ou ação rescisória (Wiederaufnahme des Verfahrens), pode ser operada de duas formas e em condições distintas: por erro processual na forma de anulação (Nichtigkeitsklage), nos termos do $\$ 579$ ZPO; por erro na base de tomada de decisão (provas etc.), por meio de processos de restituição (Restitutionsklage) ao abrigo do $\mathbb{S} 580 \mathrm{ZPO} .{ }^{17}$

14 A revogação extraordinária é que viabiliza a impugnação da sentença transitada em julgado, seja com base em vícios ostensivos ou ocultos. "Sulla base degli art. 395 e 396 c.p.c., si distingue tra revocazione ordinaria - impedisce il passaggio in giudicato della sentenza - ovvero straordinaria - proponibile anche dopo il passaggio in giudicato della sentenza - con riguardo alla natura palese o occulta dei vizi della decisione.” (FRANCALANCI, Daniela. Formulario del processo civile, annotato con la giurisprudenza - aggiornato con la riforma della semplificazione dei riti civili. Piacenza-Italia: Casa Editrice la Tribuna, 2011. v. 1, p. 482).

15 SÁNCHEZ-ARJONA, Mercedes Llorente. La revisión en el proceso civil. Boletín Mexicano de Derecho Comparado, nueva serie, año XL, n. 119, p. 585-604, maio/ago. 2007.

16 "La revisión de sentencias firmes se encuentra regulada en nuestra Ley de Enjuiciamiento Civil en el último título, el VI, que cierra el Libro II, titulado 'de la revisión de sentencias firmes', abarcando los artículos 509 a 516, configurándola como un verdadero proceso. De todo lo dicho, se extraer el carácter subsidiario de la revisión; pues sólo es admisible cuando el proceso ha terminado definitivamente, sin que quepa la posibilidad de ulteriores recursos. De esta forma no es admisible la revisión respecto de los juicios sumarios establecidos en el artículo 447 de la Lec, porque no producen el efecto de cosa juzgada y pueden volverse a discutir en otro proceso sobre el mismo objeto. La revisión comprende un doble enjuiciamiento: el iudicium rescindens y el iudicium rescisorium. Mediante el primero el Tribunal decide acerca de la existencia del vicio producido por el hecho nuevo con carácter puramente negativo. Mediante el segundo, se dicta una nueva sentencia." (NOSETE, Véase Almagro; PAULE, José y Tomé. El llamado recurso de revisión, en varios autores, instituciones de derecho procesal civil. Madrid: Trivium, 1994. p. 539).

17 "Contudo, tem de haver um meio de eliminar nas sentenças transitadas em julgado, os vícios mais graves que acusam ou que se acham sob graves vícios processuais.” (JAUERNING, Othmar. Direito processual civil. Tradução de Francisco Silveira Ramos. 25. ed. Lisboa: Almedina, 1998. p. 393). 
$\mathrm{Na}$ Itália vige a revocazione ${ }^{18}$ com natureza jurídica de ação visando à desconstituição da decisão de mérito. ${ }^{19}$

As leis canônicas, no âmbito processual, são similares às regras do Código de Processo Civil vigente no Brasil, estando prevista a restitutio in integrum e também a querela nullitatis. ${ }^{20}$ A restitutio in integrum (ação constitutiva) poderá ser proposta no quadriênio, e a querela nullitatis (ação declaratória), com prazos distintos, mais elásticos, quando se sustentar nulidade insanável (trinta anos), e mais exíguos, para a hipótese de nulidade sanável (apenas três meses). ${ }^{21}$

Portanto, há sistemas processuais que assumem a função rescisória dentro do sistema recursal, convivendo com a ideia de um remédio derradeiro que não impede o trânsito em julgado, sendo que na decisão impugnada, uma vez atingida pela procedência desse "remédio rescisório", reverte-se totalmente o tratamento, aproximando-se, em muitos casos, de algo como se nunca houvesse existido tal trânsito em julgado. Igualmente o são a requête civile e a revisão, respectivamente na França ${ }^{22}$ e Portugal. ${ }^{23}$ Por outro lado, existem sistemas que concebem a rescisória como ação. Nessa esteira, existem dispositivos na Alemanha, no Direito Canônico e no Brasil. ${ }^{24}$ Por fim, há ainda um sistema híbrido. Curioso que no modelo espanhol a revisão possui particularidades de ação, mas a sua classificação encontra-se dentro do sistema recursal, como recurso extraordinário, abrindo cabimento antes do trânsito em julgado.

\subsection{HISTÓRICO DO DIREITO PROCESSUAL E DA AÇÃO RESCISÓRIA NO DIREITO BRASILEIRO}

As Ordenações Portuguesas vigeram no Brasil no período colonial, sendo que em 1822, por ocasião da Independência, foi confirmada a vigência das Ordenações,

18 Note-se que o direito processual europeu está em franca ebulição. (BONTÀ, Silvana Dalla. L'evoluzione del diritto processuale civile nella mitteleuropea alla volta del nuovo millennio: riforme e codificazioni: tradizione e innovazione. Revista de Processo, São Paulo: RT, v. 37, n. 203, p. 293-301, jan. 2012. p. 293).

19 Codice di Procedura Civile, art. 324.

20 “A anulação, em termos estritos, diferencia-se da revogação em razão do pressuposto que a antecede. Um enunciado jurídico é anulado mediante a constituição de um contraenunciado, em decorrência da existência de vício formal ou material do enunciado anterior. A anulação, neste sentido, pressupõe sempre um vício, o que não acontece com a revogação." (CARVALHO, Aurora Tomazini. Curso de teoria geral do direito, p. 735).

21 ROCCA, Fernando Della. Istituzioni di diritto processuale canonico. Torino: Utet, 1946. p. 344.

22 MOREL, René. Traité êlémentaire de procédure civile. 2. ed. Paris: Sirey, 1949. p. 602.

23 Código de Processo Civil de Portugal, parágrafo único do art. 677.

24 Código de Processo Civil de 1939, art. 798, CPC/1973, art. 485, e CPC/2015, art. 966. 
exceto nos dispositivos que pudessem depor contra o regime imperial e a soberania brasileira, o que teve atuação prolongada até o início do século XX, por meio das Ordenações Filipinas, publicadas em 1603. O próprio Código Filipino permitia uma espécie de via rescisória da demanda julgada, a chamada "revista dos feitos". ${ }^{25}$

A Constituição de 1824 não alterou a realidade do processo civil, havendo avanços significativos no processo penal, com a abolição, por exemplo, das torturas, dos açoites e outras penas cruéis, fixando também o compromisso na elaboração de um Código Penal, estatuto esse que veio a lume em 1830. Curioso é que no texto sancionado do Código Criminal do Império do Brasil foi incluído capítulo sobre "disposição provisória acerca da administração da justiça civil". Na verdade, essa disposição foi a base do Processo Civil nas duas décadas subsequentes. ${ }^{26}$

Ainda, durante a vigência das Ordenações, o direito era regulado também por diversas leis extravagantes. Eram mesmo muitas leis extravagantes regulando o processo civil, além das Ordenações e suas alterações, sendo que três atos normativos posteriores tiveram maior importância no processo civil, no sentido de adequar a atualização legislativa à realidade brasileira da época. A primeira foi a Lei n. 556, de 25 de junho de 1850, que introduziu o Código Comercial no Brasil e disciplinou o processo no âmbito das causas comerciais; a segunda foi o Regulamento 737, de 25 de novembro de 1850; e a terceira, a entrada em vigor da Consolidação Ribas de 1876.

${ }^{25}$ O Código Filipino, com influências do direito romano e canônico, é fortemente arraigado no princípio do dispositivo, exigindo a iniciativa das partes. No seu Livro III, contém dispositivos sobre os juízes arbitradores, demanda, contestação, exceções dilatórias e peremptórias, audiências, provas, suspeição de julgadores, regulação de atos de procuradores e advogados, testemunhas, contraditas, erro do processo, sentenças, apelação, agravo, execução e respectivos embargos. Ainda, contava com dispositivo segundo o qual, se o condenado alegar que a sentença foi proferida com base em falsa prova (ex: escritura simulada ou inexistente) ou por juiz ou desembargador peitado ou subornado, era possível utilizar uma última via para reversão do resultado da sentença, uma "graça especial". O instrumento, neste caso, era a "revista dos feitos", uma espécie de procedimento rescisório da época. (ALMEIDA, Cândido (Org.). Ordenações Filipinas. Rio de Janeiro/Lisboa: Fundação Calouste Gulbenkian, 1981. Livro III, Título n. 95, p. 102).

${ }^{26}$ Nesse sentido, foi sancionado o Código Penal do Império em 1830, impulsionado por dispositivo constitucional expresso. "Art. 179. A inviolabilidade dos Direitos Civis, e Políticos dos Cidadãos Brasileiros, que tem por base a liberdade, a segurança individual, e a propriedade, é garantida pela Constituição do Império, pela maneira seguinte. I. Nenhum Cidadão pode ser obrigado a fazer, ou deixar de fazer alguma coisa, senão em virtude da Lei. (...) XVIII. Organizar-se-á quanto antes um Código Civil, e Criminal, fundado nas sólidas bases da Justiça, e Equidade. XIX. Desde já ficam abolidos os açoites, a tortura, a marca de ferro quente, e todas as mais penas cruéis.” (Constituição Política do Império do Brasil de 25 de março de 1824). 
O Regulamento, por sua vez, nos legou a organicidade dos atos processuais e sua simplificação, instituiu a publicidade das audiências, incluiu dispositivos sobre a redução dos prazos previstos no Estatuto Filipino e suprimiu exceções autuadas como incidentes, permitindo arguição e processamento direto nos autos da demanda em curso, dentre outros pontos relevantes, com evidente aplicação dos princípios da celeridade e economia processual, o que, sem dúvida, deu origem à evolução do pensamento processual aplicado hoje no Brasil. ${ }^{27}$

No Regulamento 737/1850, encontramos a regulamentação do rol de sentenças consideradas nulas (conforme o art. 680) e as respectivas formas para impugnação e obtenção da declaração de nulidade (art. 681, $\mathbb{S} 4^{\circ}$ ) - dentre elas, a apelação, o recurso de revista, os embargos à execução, além da própria ação rescisória.

A Consolidação Ribas de 1876, também chamada Consolidação das Leis do Processo Civil, foi elaborada pelo conselheiro Antônio Joaquim Ribas, nomeado pelo Governo Imperial para reorganizar aspectos processuais civis constantes das leis esparsas vigentes em um único documento. ${ }^{28}$

Com a proclamação da República, em 1889, instala-se novo ânimo reformista, e, dentre tais alterações legislativas, foram levadas a efeito a ampliação e o refinamento das regras processuais para abarcar a aplicação do Regulamento 737/1850 no âmbito civil. Era o que determinava o Regulamento 763, de 1890, sem prejuízo da aplicação concomitante das Ordenações, no que fosse compatível com o Regulamento 737/1850 em sua nova redação. ${ }^{29}$

Logo em seguida foi promulgada a Constituição Republicana de 1891, que instaurou profundas alterações no processo civil. Com inspiração no modelo americano, criou-se a forma federativa e a dualidade de justiça, instituindo a Justiça Federal e a Justiça Estadual, cada qual com competência para legislar sobre processo. Definiu-se, deste modo, que cabia à União legislar sobre processo no âmbito de sua competência e, aos Estados, instituir os Códigos Estaduais de Processo Civil, tomando-se por base a legislação processual instituída pela União Federal. ${ }^{30}$

27 O Regulamento 737 é considerado pela doutrina como o primeiro Código Processual brasileiro. (SANTOS, Moacyr Amaral. Primeiras linhas de direito processual civil. 29. ed. São Paulo: Saraiva, 2012. v. 1, p. 52).

${ }^{28}$ Elaborada pelo conselheiro Ribas, a Consolidação das Leis do Processo Civil passou a ter força de lei, conforme determinado pela resolução imperial de dezembro de 1876.

29 Trata-se da República Velha que se prolonga até 1930. (FAUSTO, Boris. História do Brasil. 14. ed. São Paulo: Editora da Universidade de São Paulo, 2012. p. 482).

30 PONTES DE MIRANDA, Francisco Cavalcanti. A ação rescisória contra as sentenças. São Paulo: Livraria Jacintho, 1934. p. 84. 
Surgiu nesse período o Código Processual da Bahia de 1915 e, logo depois, o de São Paulo - esses foram os mais importantes na aplicação do direito pátrio do período, a despeito de não conterem maiores inovações com relação à legislação anteriormente vigente. ${ }^{31}$ Havia códigos estaduais que, ao invés de dar soluções claras no rumo da cientificidade, que requer uma clara codificação, contribuíam para instaurar uma verdadeira confusão processual, com dispositivos pouco precisos sob a ótica da técnica processual. Para ilustrar esse aspecto, alguns objetivavam o efeito rescisório no manejo dos embargos à execução. ${ }^{32}$ Nessa esteira, previu-se a anulação da sentença, que, para aquele sistema positivo, poderia ser suscitada por meio de embargos à execução. Tal disposição constou expressamente no Código de Processo de Minas Gerais (art. 174, $\mathbb{3} 3^{\circ}$ ), no Código de Processo de Santa Catarina (art. 1.845, III), no Código de Processo do Rio de Janeiro (art. 2.277, b), no Código de Processo de Pernambuco (art. 163, $\mathbb{S} 2^{\circ}$ ), no Código de Processo da Bahia (art. 1.362, $\mathbb{S} 2^{\circ}$ ), no Código de Processo de São Paulo (art. 358, II), no Código de Processo do Espírito Santo (art. 280, III) e no Código de Processo do Distrito Federal (art. 303, III). ${ }^{33}$

Como no exemplo dado, nota-se facilmente que a elaboração de um Código Estadual esbarrava nos parcos conhecimentos dos legisladores, razão pela qual vários Estados não se utilizaram da prerrogativa de estadualização legislativa do processo civil, continuando a apoiar seus processos pelas regras do Processo Civil Federal. $^{34}$

Nesse sentido, a autorização constitucional para vigência de códigos estaduais mostrou-se ineficiente, sobrevindo nova Constituição em 1934, definindo a competência da União para legislar sobre Processo Civil, instituindo a competência supletiva dos Estados, apenas para matérias não reguladas pela União. A comissão para elaboração de um novo código nacional foi nomeada em 1937, mas seus integrantes não se entendiam, estendendo no tempo um trabalho infrutífero. Foi nesse ambiente que o processo civil veio a ser recentralizado, abolindo-se o permissivo do processo estadual. Assim, um dos integrantes da comissão, Pedro Batista Martins, apresentou o projeto do novo Código de Processo Civil de âmbito nacional, o qual, por sua vez, passou a ser lei no mesmo ano de sua apresentação,

31 DIÓGENES, Nestor. Da ação rescisória. São Paulo: Saraiva, 1938. p. 30.

32 AMERICANO, Jorge. Da acção rescisória dos julgados no direito brasileiro. São Paulo: Typographia e Papelaria de Vanorden, 1922. p. 117.

33 AMERICANO, Jorge. Estudo teórico e prático da ação rescisória dos julgados no direito brasileiro. 3. ed. São Paulo: Acadêmica, 1936. p. 101.

34 PONTES DE MIRANDA, Francisco Cavalcanti. Tratado da ação rescisória das sentenças e de outras decisões. 4. ed. Rio de Janeiro: Forense, 1964. 
por meio do Decreto-lei n. 1.608, de 1939. Aquele CPC continha o timbre da modernidade na parte geral, mas era antiquado na parte especial. ${ }^{35} \mathrm{Um}$ exemplo desse atraso legislativo é que continuava e persistia no erro dos códigos estaduais, ou seja, manteve os embargos à execução com base na nulidade da sentença oriunda na falta de citação no processo de conhecimento, conforme disposição do art. 1.010, inciso I; e também dispôs sobre o cabimento da ação rescisória com base na nulidade da sentença, na dicção do art. 798, ambos dispositivos do CPC de 1939 - manifestou-se dupla chance de o vencido impugnar a sentença transitada em julgado, pelo mesmo motivo. O equívoco legislativo foi manifesto.

O Código de 1939 nasceu defeituoso. Durante sua aplicação foi se verificando que ele próprio emperrava a jurisdição com a possibilidade de vários recursos sobre a temática processual controvertida no próprio texto codificado. Depois de mais de 30 anos de sua vigência, a própria praxe forense exigiu a reformulação, na verdade um novo código.

Os trabalhos foram iniciados em 1970, sob a batuta do então ministro da Justiça, Alfredo Buzaid. O anteprojeto do Código de Processo Civil recebeu diversas emendas e, em 11 de janeiro de 1973, foi promulgado pela Lei n. 5.869.36

O CPC de 1973 representou, sem dúvida, um marco histórico no avanço legislativo dos dispositivos processuais no campo civil. Desataca-se a correção de falhas existentes no texto da codificação anterior (1939), a reforma integral do processo de execução e cautelar, bem como a sistematização do procedimento de jurisdição voluntária, verdadeira inovação legislativa. ${ }^{37}$ Ainda, o CPC de 1973 solucionou problemas pontuais, como o da definição do cabimento da ação rescisória para ataque de vícios rescisórios contidos na sentença de mérito (art. 485) e sua admissão em decisão meritória com trânsito em julgado nos embargos à execução, com permissivo diante da ausência ou nulidade de citação (art. $745, \mathrm{I}) .^{38}$

35 "Dizia-se, com razão, que dois espíritos coabitavam o Código, formando uma parte geral impregnada de ideias novas, enquanto as que tratavam dos procedimentos especiais, dos recursos e da execução se ressentiam 'de um execrável ranço medieval'." (THEODORO JÚNIOR, Humberto. Curso de direito processual civil. 53. ed. Rio de Janeiro: Forense, 2012. v. 1 , p. 17).

36 PONTES DE MIRANDA, Francisco Cavalcanti. Comentários ao CPC. Rio de Janeiro: Forense. 1975. t. VI, p. 202.

37 MARQUES, José Frederico. Manual de direito processual civil. 2. ed. Campinas: Millennium, 1998. v. 1, p. 116.

38 VIDIGAL, Luís Eulálio de Bueno. Comentários ao Código de Processo Civil. São Paulo: RT, 1974, $\mathbb{S} \int 23$ a 25, p. 31. 
Após anos de vigência e várias alterações legislativas, com atualizações importantes, o CPC de 1973 permaneceu resistente ao tempo. Mas essas alterações acabaram por desfigurar a organicidade do CPC. Há de se notar que o CPC, vigente por quase quatro décadas (Lei n. 5.869/73), sofreu profundas alterações a partir de 1994, lideradas pelos Ministros Athos Gusmão Carneiro e Sálvio de Figueiredo Teixeira. São exemplos: a introdução da antecipação de tutela, a alteração do regime do agravo retido, da adjudicação na execução, o cumprimento de sentença, o que permitiu a operabilidade do sistema diante das mudanças sociais. Diante de tantas mudanças, a codificação perdeu sua identidade, gerou enfraquecimento da coesão entre as normas processuais, sendo necessária nova codificação. ${ }^{39}$

A existência de uma zona cinzenta sobre o cabimento da ação rescisória e de ação anulatória levou intérpretes renomados a divergirem em dadas situações. No novo CPC, ficaram mais claras as hipóteses de cabimento de ação rescisória e de ação anulatória, eliminando-se tais dúvidas, com soluções como a de deixar sentenças homologatórias como categoria de pronunciamento impugnável pela ação anulatória, ainda que se trate de decisão de mérito, isto é, que homologa transação, reconhecimento jurídico do pedido ou renúncia à pretensão. ${ }^{40}$ Além disso, estudou-se a alteração do prazo para interposição da ação rescisória. ${ }^{41}$ Por fim, é

39 Além disso, critica-se o excesso de recursos e a morosidade da justiça, razão pela qual foi proposto o projeto do novo CPC. (MARINONI, Luiz Guilherme; MITIDIERO, Daniel. O projeto do CPC: críticas e propostas. São Paulo: RT, 2010, p. 178).

40 "Altera-se topograficamente o art. 929 para inseri-lo após o art. 247. A ação anulatória de que trata este artigo não é uma ação de competência de tribunal. O enunciado é geral, refere-se à invalidação de atos processuais e deve, portanto, estar no trecho do Código dedicado às invalidades processuais. Justificativa. A troca 'atos de disposição' para 'atos negociais’ justifica-se pela generalidade da segunda expressão. Ato dispositivo é espécie de ato negocial. Percebe-se, por exemplo, que o projeto autoriza o ajuizamento de ação anulatória de ato praticado em execução, como a adjudicação. A adjudicação não é ato dispositivo, mas é ato negocial. A outorga de poderes também não é ato dispositivo, mas é ato negocial. Além da mudança terminológica, é preciso compatibilizar o uso da ação anulatória com a ação rescisória. Se o ato dispositivo foi homologado pelo juiz e houve trânsito em julgado, aí já não caberá mais ação anulatória, só ação rescisória.” (TEIXEIRA, Paulo. Relator: Deputado. Senado Federal. Relatório da Comissão Especial destinada a proferir parecer ao Projeto de Lei n. 6.025, de 2005, ao Projeto de Lei n. 8.046, de 2010, ambos do Senado Federal, e outros, que tratam do "Código de Processo Civil” e que revogam a Lei n. 5.869, de 1973 - com apresentação do substitutivo, 09.01.2013, p. 312).

${ }^{41} \mathrm{Na}$ primeira versão, previu-se um prazo ainda menor para interposição da ação rescisória, qual seja, de um ano, a contar do trânsito em julgado material. (MARINONI, Luiz Guilherme; MITIDIERO, Daniel. O projeto do CPC, p. 177). 
importante destacar que os juristas debateram sobre a atuação do processo, deslocando-se o eixo individualista operado no CPC/1973 para o viés das ações coletivas, ${ }^{42}$ que hoje são regradas por leis esparsas. Essas foram, em linhas gerais, tendências do pensamento jurídico-processual presentes na elaboração do atual Código de Processo Civil, publicado por meio da Lei n. 13.105, de 16 de março de $2015 .{ }^{43}$

${ }^{42}$ Será real a necessidade de institucionalização do "processo coletivo" em sistema codificado? Essa e outras questões estão em aberto, com projeto em tramitação. (ALVIM, Eduardo Arruda. Coisa julgada e litispendência no anteprojeto de código brasileiro de processos coletivos. In: MENDES, Aluísio Gonçalves de Castro; GRINOVER, Ada Pellegrini; WATANABE, Kazuo (Coord.). Comentários ao anteprojeto de código brasileiro de processos coletivos. São Paulo: RT, 2007. p. 232).

43 A Comissão de Juristas (Teresa Arruda Alvim Wambier - Relatora, Adroaldo Furtado Fabrício, Humberto Theodoro Júnior, Paulo Cesar Pinheiro Carneiro, José Roberto dos Santos Bedaque Almeida, José Miguel Garcia Medina, Bruno Dantas, Jansen Fialho de Almeida, Benedito Cerezzo Peireira Filho, Marcus Vinicius Furtado Coelho e Elpídio Donizetti Nunes - membros), liderada pelo Ministro Luiz Fux, entregou o Anteprojeto do Novo Código de Processo Civil ao Presidente do Senado Federal, Senador José Sarney, em 8 de junho de 2010. (FUX, Luiz et al. Anteprojeto do novo Código de Processo Civil. Comissão de Juristas Responsável pela Elaboração do Anteprojeto do novo Código de Processo Civil. Brasília: Senado Federal, Subsecretaria de Edições Técnicas, 2010. p. 6). 